\title{
Application of Sulfonated GMA-g-non Woven PE Fabric for the Efficient Removal of Methylene Blue Dye from Wastewater
}

\author{
Md. Sohel Rana ${ }^{1,2}$, Nazia Rahman ${ }^{1, *}$, Tofail Ahmed Chowdhury ${ }^{2}$, Nirmal Chandra Dafader ${ }^{1}$ \\ Shahnaz Sultana ${ }^{1}$, Md. Nabul Sardar ${ }^{1}$, Md. Nahid Kayser ${ }^{1}$ \\ ${ }^{1}$ Nuclear and Radiation Chemistry Division, Institute of Nuclear Science and Technology, Atomic Energy Research Establishment, \\ Bangladesh Atomic Energy Commission, Dhaka, Bangladesh \\ ${ }^{2}$ Department of Chemistry, University of Dhaka, Dhaka, Bangladesh
}

Email address:

naziabaec@gmail.com (N. Rahman)

${ }^{*}$ Corresponding author

\section{To cite this article:}

Md. Sohel Rana, Nazia Rahman, Tofail Ahmed Chowdhury, Nirmal Chandra Dafader, Shahnaz Sultana, Md. Nabul Sardar, Md. Nahid Kayser. Application of Sulfonated GMA-g-non Woven PE Fabric for the Efficient Removal of Methylene Blue Dye from Wastewater. American Journal of Polymer Science and Technology. Vol. 7, No. 1, 2021, pp. 1-9. doi: 10.11648/j.ajpst.20210701.11

Received: November 26, 2020; Accepted: December 28, 2020; Published: January 15, 2021

\begin{abstract}
An environmental affable, economically feasible and reusable sulfonated adsorbent were constructed by gamma radiation grafting of glycidyl methacrylate (GMA) on non-woven polyethylene fabric and subsequent chemical modification. Highest graft yield of $343.31 \%$ was obtained at favourable conditions: $30 \mathrm{kGy}$ radiation dose, $5 \%$ monomer concentration, adding up of $0.5 \%$ Tween- 20 as an additive, $4 \mathrm{~h}$ reaction time. The epoxide group containing GMA-g-PE film were functionalized through sulfonation. The adsorbent was identified by Fourier Transform Infrared (FTIR), Scanning Electron Microscopy (SEM) and Thermo-gravimetric Analysis (TGA). The aqueous solutions of methylene blue were prepared in various concentrations and adsorption behavior by the developed sulfonated-GMA-g-PE film were investigated. MB uptake capacity at different environment such as contact time, $\mathrm{pH}$ and initial MB concentration were identified. The adsorption of $\mathrm{MB}$ is highly $\mathrm{pH}$ dependent and utmost sorption was found at $\mathrm{pH}$ 7. The kinetic adsorption data were interpreted by pseudo-first-order and pseudo-second-order equations. Pseudo-first-order rate kinetic model is more applicable for the sorption process due to its higher correlation coefficient. From the two isotherm model Langmuir and Fruendlich, Fruendlich model attuned best with the MB sorption as presented by higher correlation coefficient. The MB uptake capacity of the sorbent obtained from Langmuir model was $500 \mathrm{mg} / \mathrm{g}$. Futhermore, the adsorbent could be reformed and reused repeatedly for the sorption of MB from waste water.
\end{abstract}

Keywords: Radiation, GMA, Methylene Blue, Isotherm, Kinetics

\section{Introduction}

Undesirable amounts of waste water containing color effluents are released from printing cosmetics, food coloring, dying, textile and papermaking industries [1]. Worldwide 10,000 commercial dyes are available and approximately $7 \times 105$ tones different types of dyes are formed each year [2]. Annually $12 \%$ of dyes produced are discharged as effluents from dying, textiles and related industries [3]. Even in small amounts of dyes revealing into water bodies can have a enormous repulsive consequence on the food web and aquatic life. It can create dermatitis, skin irritation and allergic reactions. Several of them are even mutagenic and carcinogenic for human beings and aquatic organisms [4]. Alzheimer's disease in human body is also created by dyes [5]. On the other hand, it is seen that most of dyes are resistant to biodegradation and photo degradation [6-8]. So, it is very important to treat dye containing wastewater. Up to present time, several types of wastewater treatment techniques such as coagulation and flocculation methods [9], electro-coagulation [10] membrane separation [11], oxidation or ozonation [12, 13] and adsorption have been employed to eliminate dyes. Among these techniques, it is seen that for eliminating dyes and other pollutants adsorption is an efficient, lower cost, moderately simple and potentially useful technique $[14,15]$. Several types of adsorbents 
are developed that are used to eradicate dyes from waste water [16-23]. Due to comparatively lower adsorption capacity and secondary contamination of adsorbents many of them are not appropriate [24]. Uses of graft polymers has become new technique now. Elevated adsorption capacity and reusability of the adsorbent trim down the chance of creating secondary toxic waste. In case of grafting, monomers form covalent bonding to the polymer backbone. There are several advantages of polymer grafting. Grafted monomer can incorporate different functions with parent polymer but the mechanical property of the parent polymer is conserved $[25,26]$. It is seen that over plasma treatment, decomposition of chemical initiators, oxidation of polymers etc, radiation grafting are more suitable as it has high penetration power to the polymer backbone and it forms mostly homogeneous free radicals very fast [27]. In the present study, sulfonated-GMA-g PE adsorbent was made by radiation induced grafting of GMA on PE and subsequent chemical treatment. The adsorbent can adsorb cationic dye methylene blue from aqueous solution. MB uptake capacity at different environment such as contact time, $\mathrm{pH}$ and initial $\mathrm{MB}$ concentration were identified. Kinetics and isotherm of $\mathrm{MB}$ adsorption were determined. Release of adsorbed MB and once more use of the adsorbent was also performed.

\section{Experimental}

\subsection{Materials and Reagents}

The non-woven polyethylene (PE) fabric that was obtained from Kurashiki MFG Co was used to prepare the adsorbent. Glycidyl methacrylate (GMA, $\mathrm{CH}_{2}=\mathrm{CCH}_{3} \mathrm{COOCH}_{2} \mathrm{CHOCH}_{2}$ ), Polyoxyethylene sorbitan monolaurate (Tween-20), Sodium sulphite, Sodium bisulphate were supplied by Sigma Aldrich (USA) and used without further purification. Hydrochloric acid $(\mathrm{HCl})$, sodium hydroxide and Isopropyl alcohol (IPA) were purchased from Merck, Germany. Methylene Blue (MB) (Fluka, Switzerland), was used for the determination of MB uptake capacity of the adsorbent.

\subsection{Preparation of Adsorbent}

The preparation of adsorbent based on non-woven

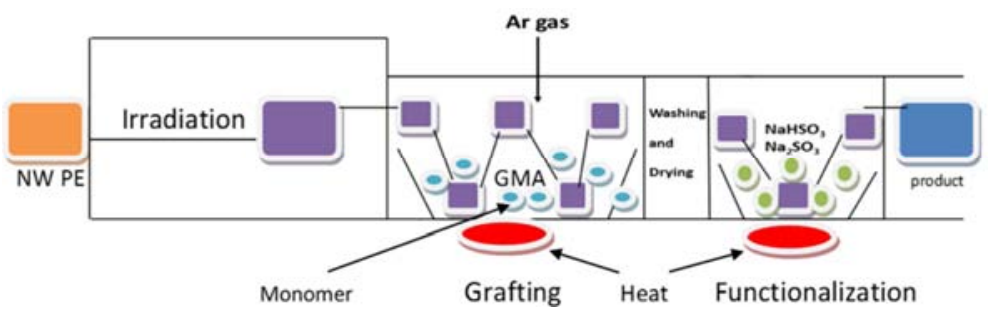

Figure 1. Preparation of sulfonated adsorbent from non-woven polyethylene for methylene blue adsorption from waste water.

\subsection{Thermo Gravimetric Analysis}

The thermal gravimetric analysis (TGA) under nitrogen environment of PE fabric and GMA-g-PE fabric sorbent $(2$ $\mathrm{mg}$ ) were performed from $25^{\circ} \mathrm{C}$ to $480^{\circ} \mathrm{C}$ with a heating rate of $10^{\circ} \mathrm{C} / \mathrm{min}$ from $25^{\circ} \mathrm{C}$ to $480^{\circ} \mathrm{C}$ and with a flow rate of 20 $\mathrm{ml} / \mathrm{min}$ on a Perkin-Elmer TGA 7-thermal analyzer. polyethylene (PE) fabric were conducted in two steps. In the first step the PE fabric was cut into the size of $8 \mathrm{~cm} \times 2 \mathrm{~cm}$ and was irradiated by gamma radiation from Co- 60 source. The radiation dose applied was $30 \mathrm{kGy}$ at ambient temperature. Gamma irradiated PE film was kept in dry-ice temperature until use. At room temperature $\left(25^{\circ} \mathrm{C}\right), 5 \mathrm{wt} \%$ monomer GMA and $0.5 \mathrm{wt} \%$ Tween-20 as emulsifier was added to deionised water to prepare the monomer GMA emulsion by stirring with a mechanical stirrer for $0.5 \mathrm{~h}$. To remove dissolved oxygen the emulsion of GMA was bubbled for 40 minutes with Argon gas. The irradiated PE fabric was put into a glass bottle and it was fully filled by de-aerated GMA emulsion. To prevent inclusion of oxygen from air into the GMA-emulsion of bottle it was compactly closed with a lid. The grafting reaction was performed at $80^{\circ} \mathrm{C}$ in a water bath up to $4 \mathrm{~h}$. The constructed GMA-g-PE film was washed repeatedly with deionized water to remove remaining monomer and homopolymer of GMA and dried up in a vacuum oven to steady weight. The degree of grafting was calculated as follows:

$$
\text { Degree of grafting }(\%)=(\mathrm{Wg}-\mathrm{W} 0) / \mathrm{W} 0 \times 100
$$

Where, Wg is the dry weight of GMA grafted PE fabric and $\mathrm{W}_{0}$ is the dry weight of PE fabric.

In the second step, GMA-g-PE fabric was deeped in sodium bisulphite, sodium sulphite, iso-propanol and water solutions at the ratio of $10 / 3 / 10 / 77 \mathrm{wt} \%$ and the reaction was conceded at $80^{\circ} \mathrm{C}$ at constant heating up to $6 \mathrm{~h}$ [28]. Subsequently, sulfonated-GMA-g-PE adsorbent was washed again and again with deionized water until neutral and conversion of epoxide group (X) to sulfonate group were calculated as follows:

$$
\text { Conversion }(\mathrm{X})=\left[\frac{W s-W g}{104} / \frac{W g-W o}{142}\right] \times 100
$$

Where, $\mathrm{W}_{0}, \mathrm{Wg}$ and $\mathrm{Ws}$ are the dry weight of PE fabric, GMA-g-PE fabric and sulfonated-GMA-PE adsorbent respectively. 142 and 104 are the molecular weight of GMA and sodium bisulphate. Figure 1 shows the preparation of sulfonate group containing MB adsorbent. desiccated in a vacuum oven to stable weight. The

\subsection{FTIR (ATR) Spectroscopy}

We have characterized the PE and GMA-g-PE by FTIR (ATR) spectrophotometer (IRPrestige 21 supplied by Shimadzu Corporation, Kyoto, Japan) in the range 700-4000 $\mathrm{cm}^{-1}$ (resolution $4 \mathrm{~cm}^{-1}$, number of scans: 20 times). 


\subsection{Scanning Electron Microscopy}

The morphological experiment of the PE and GMA-g-PE febric was performed by using scanning electron microscopy (SEM) of Model JSM-6490LA, JEOL at an accelerating voltage of $20 \mathrm{kV}$. The SEM specimens were sputter coated with platinum.

\subsection{Determination of MB Adsorption}

The constructed sulfonated-GMA-g-PE films were immersed into aqueous solutions of $\mathrm{MB}$ at room temperature $\left(25^{\circ} \mathrm{C}\right)$. Under different environment such as $\mathrm{pH}$, contact time and initial MB concentration the adsorption was pursued. We have used $\mathrm{HCl}$ and $\mathrm{NaOH}$ solution for $\mathrm{pH}$ adjustment of the solutions. Aqueous MB solutions concentrations before and after sorption were determined by a UV spectro-photometer (wave length 663 $\mathrm{nm})$. The MB dye sorption capacity of the constructed fabric was calculated using the subsequent equation:

$$
\mathrm{Q}=\left(\mathrm{C}_{1}-\mathrm{C}_{2}\right) \mathrm{V} / \mathrm{W}
$$

Where, $\mathrm{Q}$ is the sorption amount ( $\mathrm{mg} / \mathrm{g}$ of adsorbent), $\mathrm{W}$ is the weight of the sulfonated-GMA-g- PE fabric $(\mathrm{g})$, $\mathrm{V}$ is the volume of solution (L), and $\mathrm{C}_{1}$ and $\mathrm{C}_{2}$ are the concentrations $(\mathrm{mg} / \mathrm{L})$ of dye before and after sorption, respectively.

\subsection{Desorption of $M B$}

MB dye desorption from the sorbent fabric was determined by soaking in $2 \mathrm{M}$ aqueous $\mathrm{HNO}_{3}$ for $24 \mathrm{~h}$. Percentage of desorption was calculated using the equation stated below:

$$
\text { Percent desorption }=\{\text { Ions desorbed }(\mathrm{mg}) / \text { Ions adsorbed by }
$$
the film $(\mathrm{mg})\} \times 100$

\section{Results and Discussion}

\subsection{Preparation and Characterizations of the Adsorbent Film}

\subsubsection{Preparation of the Adsorbent Film}

We have prepared sulfonated-GMA-g-PE adsorbent by gamma radiation (Pre-irradiation method). At first gamma irradiation was exposed to the non woven PE polymer backbone to form primary free radicals. Then, the monomer GMA solution mixing in a suitable solvent was added to the irradiated polymer for grafting. In the reaction graft growing chain and termination reaction was occurred. Finally the graft copolymer was produced. In pre-irradiation technique, monomer is not irradiated directly and formation of homo polymer is relatively lower than simultaneous irradiation technique. The GMA grafted $\mathrm{PE}$ film was functionalized by sulfonation reaction and the reaction was performed at $70^{\circ} \mathrm{C}, 80^{\circ} \mathrm{C}$ and $90^{\circ} \mathrm{C}$ at constant heating up to $6 \mathrm{~h}$ for the determination of effect of temperature on sulfonation. It was observed that comparatively homogeneous grafting was occurred at $80^{\circ} \mathrm{C}$.

Grafting was carried out at $20 \mathrm{kGy}, 30 \mathrm{kGy}$ and $40 \mathrm{kGy}$ to study the effect of total dose of gamma radiation, maximum grafting and adsorption was found at $30 \mathrm{kGy}$ radiation dose.
$2.5 \%, 5 \%$ and $7.5 \%$ GMA solutions were used to optimize degree of grafting. Higher grafting was observed at $5 \%$ GMA solution. $343.31 \%$ graft yield was obtained (favourable conditions $30 \mathrm{kGy}$ radiation dose, $5 \%$ monomer concentration, adding up of $0.5 \%$ Tween- 20 as an additive, $4 \mathrm{~h}$ reaction time),

Epoxide group containing GMA-g-PE film can be easily functionalized. Using $343.31 \%$ degree of grafting, the sulfonation was performed in sodiumbisulphite, sodium sulphite and isopropanol and water solutions in the ratio of $10 / 3 / 10 / 77$ wt $\%$ at $80^{\circ} \mathrm{C}$ at constant heating up to $6 \mathrm{~h}$. The constructed sulfonated GMA grafted films (G-343.31\%) were modified by treatment with $\mathrm{NaOH}$ which increased the metal ion adsorption capacity of the films largely.

\subsubsection{FTIR Analysis}

FTIR spectrum of PE film and GMA grafted PE film were performed. IR spectrum of the PE film is shown in (Figure 2(a)). From IR spectrum of PE two types of vibrations, $\mathrm{C}-\mathrm{H}$ stretching and $\mathrm{C}-\mathrm{H}$ deformation vibrations were found. At $2910 \mathrm{~cm}^{-1}$ and $2845 \mathrm{~cm}^{-1} \mathrm{C}-\mathrm{H}$ asymmetric and symmetric stretching vibrations are seen. $\mathrm{C}-\mathrm{H}$ bending, wagging and rocking deformation of $\mathrm{CH}_{2}$ group are found at 1463,1369 and $721 \mathrm{~cm}^{-1}$ respectively.

Figure 2(b) shows the evidence for the grafting of GMA on PE film, peaks at $1716 \mathrm{~cm}^{-1}$ indicates $\mathrm{C}=\mathrm{O}$ stretching vibrations, peaks at 1273 and $1147 \mathrm{~cm}^{-1}$ represents symmetric and asymmetric vibration of C-O in GMA and peaks for epoxy rings were appreared at 912 and $856 \mathrm{~cm}^{-1}$.

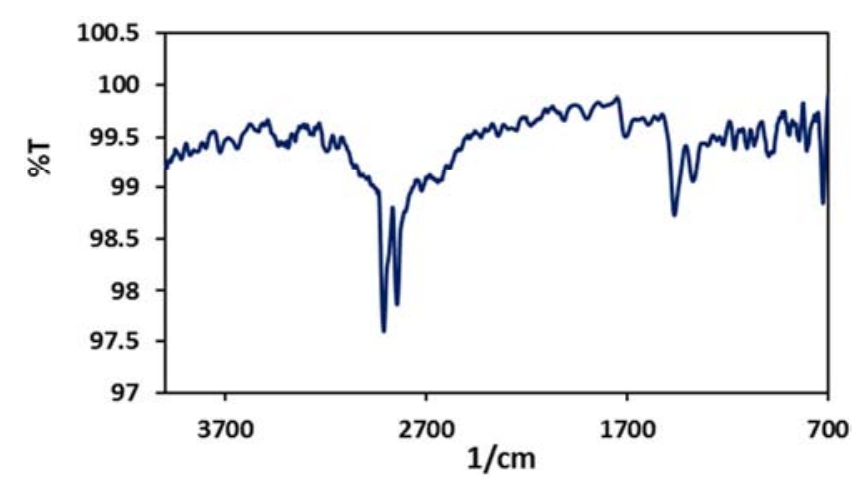

(a)

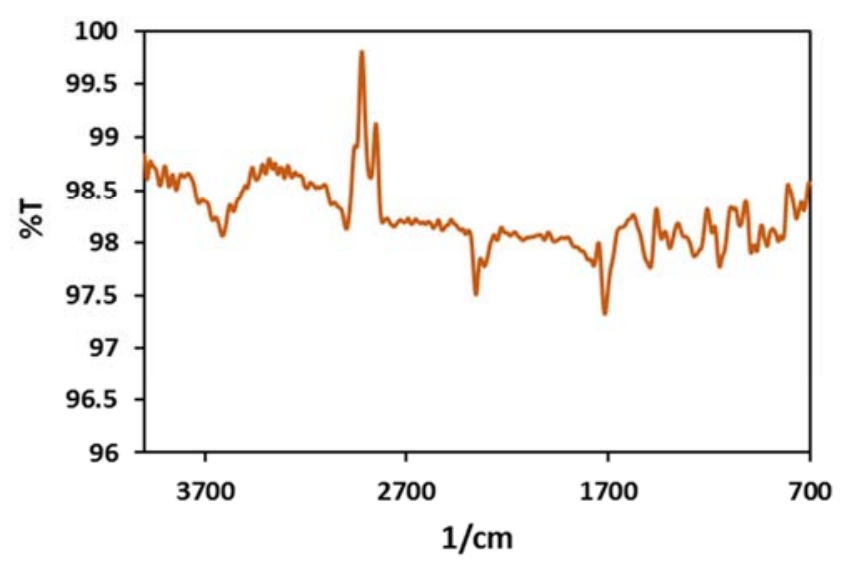

(b)

Figure 2. IR spectrum of (a) PE fabric (b) GMA grafted non-woven PE fabric. 

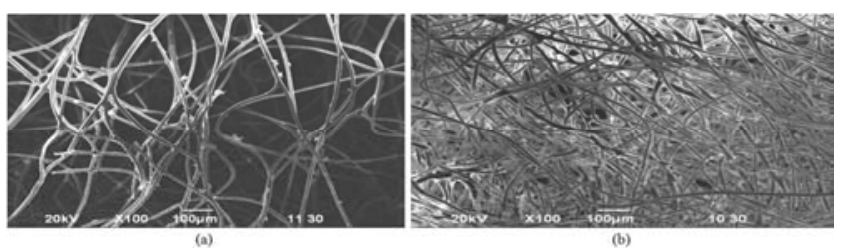

Figure 3. SEM image of (a) non-woven PE fabric (b) GMA grafted nonwoven PE fabric.

\subsubsection{SEM Analysis of the Adsorbent}

The SEM image of PE and GMA-g-PE fabrics are shown in Figure. 3. It was seen that the morphological structure changes from non woven PE to GMA grafted non woven PE and also physical appearance. In the SEM image, new graft chains and cross linked chains were found which provides proof of grafting.

\subsubsection{Thermo-Gravimetric Analysis of the Adsorbent}

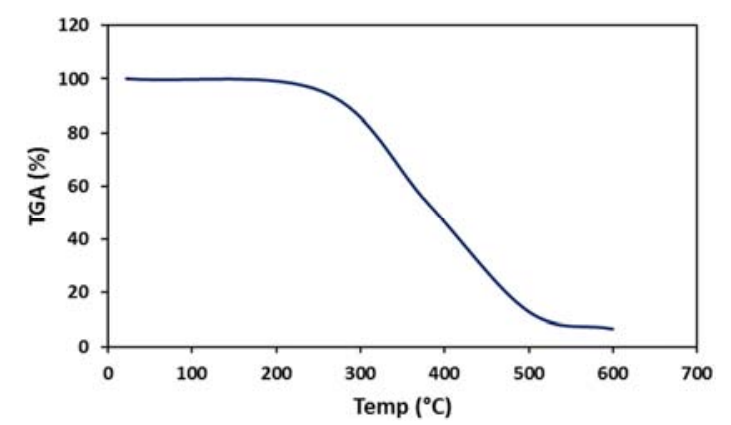

(a)

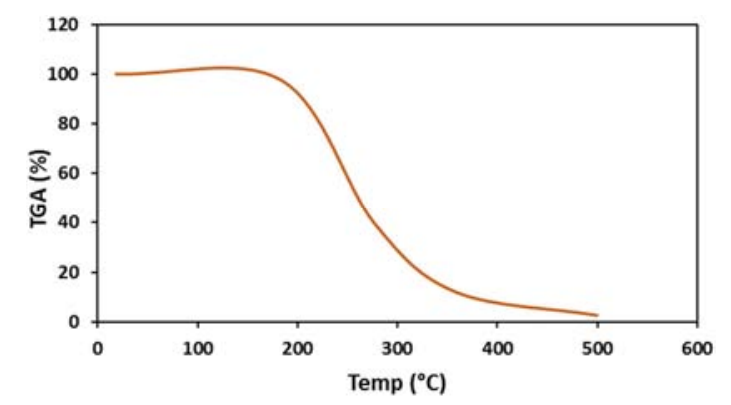

(b)

Figure 4. TGA thermo-gram of (a) non-woven PE fabric (b) GMA grafted non-woven PE fabric.

The thermo-gravimetric analysis (TGA) for the non-woven $\mathrm{PE}$ film is presented in figure 4(a). Non-woven PE film shows thermal firmness up to $200^{\circ} \mathrm{C}$ and after $200^{\circ} \mathrm{C}$ it starts to degrade. It shows a three decomposition steps, i.e., $200^{\circ} \mathrm{C}-$ $255^{\circ} \mathrm{C}, 255^{\circ} \mathrm{C}-499^{\circ} \mathrm{C}$ and above $499^{\circ} \mathrm{C}$. At $200^{\circ} \mathrm{C}-255^{\circ} \mathrm{C}$, $4.81 \%$ of the $\mathrm{PE}$ decomposes, at $255^{\circ} \mathrm{C}-379^{\circ} \mathrm{C}, 46.33 \% \mathrm{PE}$ decomposes, at $379^{\circ} \mathrm{C}-499^{\circ} \mathrm{C}, 87.08 \% \mathrm{PE}$ decomposes and at above $499^{\circ} \mathrm{C}, 93.38 \% \mathrm{PE}$ decomposes.

Figure 4(b) represents the thermo-gravimetric analysis of the GMA grafted non-woven PE film. GMA grafted nonwoven $\mathrm{PE}$ film shows thermal firmness up to $180^{\circ} \mathrm{C}$ and higher than $180^{\circ} \mathrm{C}$ it starts to degrade. It shows a four decomposition state, i.e. at $180^{\circ} \mathrm{C}-184^{\circ} \mathrm{C}, 2.52 \%$ of the grafted $\mathrm{PE}$ decomposes, at $184^{\circ} \mathrm{C}-277^{\circ} \mathrm{C}, \quad 60.36 \%$ grafted $\mathrm{PE}$ decomposes, at $277^{\circ} \mathrm{C}-358^{\circ} \mathrm{C}, 88.02 \%$ grafted $\mathrm{PE}$ decomposes and above $358^{\circ} \mathrm{C}, 97.38 \%$ grafted $\mathrm{PE}$ decomposes.

\subsection{Investigation of MB Adsorption by the Sulfonated-GMA-g-PE Adsorbent}

\subsubsection{MB Adsorption by GMA-g-PE Adsorbent}

The prepared sulfonated-GMA-g-PE adsorbent is used for the uptake of $\mathrm{MB}$ from aqueous solution. Figure 5 shows the physical appearance of sulfonated-GMA-g-PE adsorbent before and after MB adsorption.

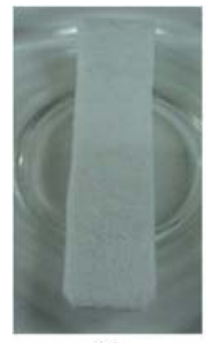

(a)

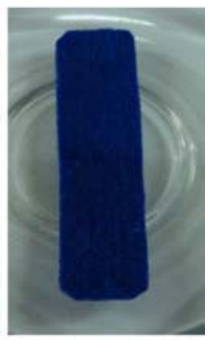

(b)
Figure 5. Sulfonated adsorbent before (a) and after (b) MB adsorption.

\subsubsection{Proposed Adsorption Mechanism}

Proposed adsorption mechanism for MB adsorption by sulfonated-GMA-g-PE is shown in Figure 6.
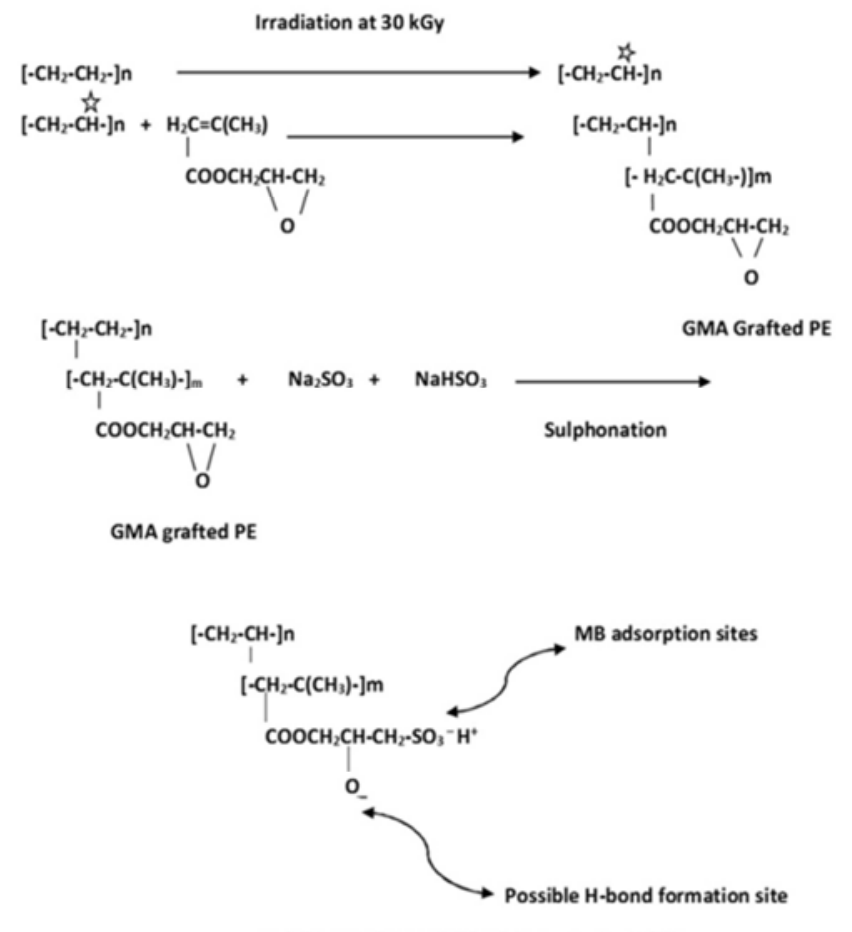

Sulphonated GMA grafted non-woven PE film

Figure 6. Proposed adsorption mechanism for $M B$ adsorption by sulfonatedGMA-g-PE.

\subsubsection{Effect of Adsorbent Weight}

The effect of sulfonated-GMA-g-PE adsorbent weight on adsorption capacity of $\mathrm{MB}$ is shown in figure 7 . It was seen that the MB uptake capacity of the adsorbent decreases with rising of adsorbent weight at the same volume and starting concentration of the MB solution. It is due to the reduction of 
the external area of the reaction site in a unit weight.

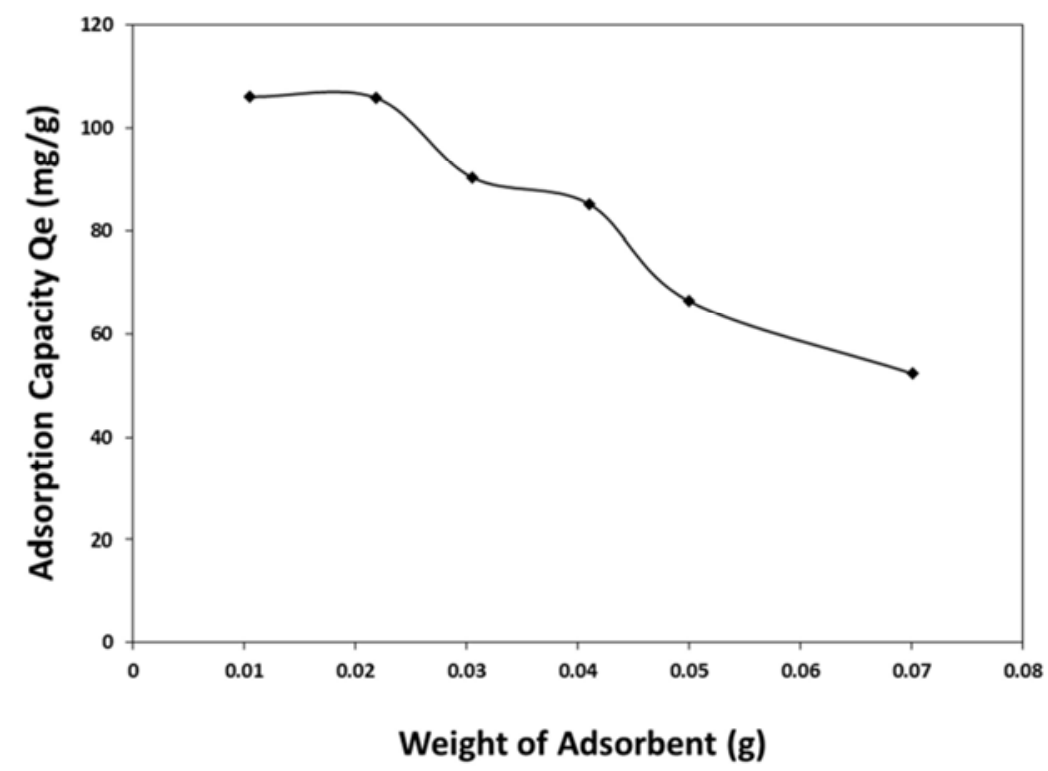

Figure 7. The effect of sulfonated-GMA-g-PE adsorbent on adsorption capacity of MB (conditions: Initial conc. 200ppm, pH 5.7, Volume $20 \mathrm{~mL}$, Contact time 48h).

\subsubsection{Effect of Contact time on Adsorption}

The consequence of contact time on the adsorption amount of $\mathrm{MB}$ upto $72 \mathrm{~h}$ at initial $\mathrm{pH} 5.7$ and the starting $\mathrm{MB}$ concentration $200 \mathrm{ppm}$ for sulfonated-GMA-g-PE films were calculated. From Figure 8, it can be accomplished that the starting MB uptake rate is fast, then it slows down and gradually reaches to equilibrium at $48 \mathrm{~h}$ with the maximum adsorption of $73.85 \mathrm{mg} / \mathrm{g}$. Almost $52 \%$ of the adsorption occurred within the first 5 hours. The early fast MB uptake rate is related to large initial concentration of MB and big large number of available active sites on sulfonated-GMA-gPE adsorbent. This first MB uptake rate also indicates that most of the reactive adsorption sites are to be found in front of the surface of the sulfonated-GMA-g-PE adsorbent particle and easily attracted by MB.

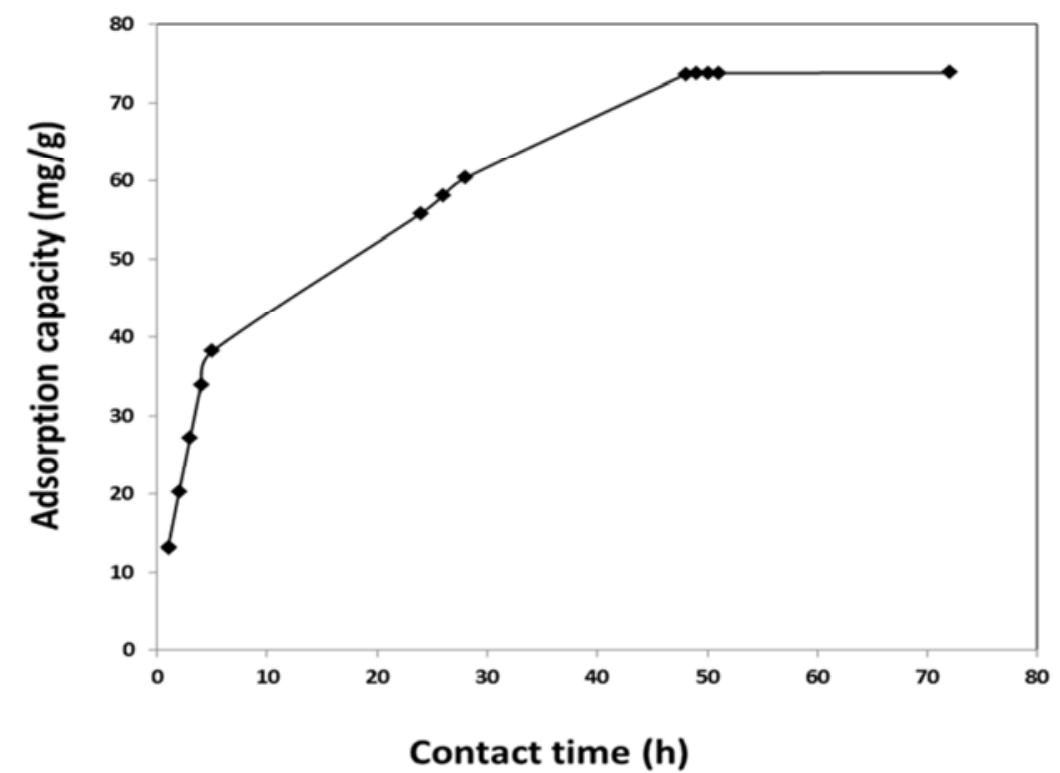

Figure 8. Effect of contact time on MB adsorption by sulfonated-GMA-PE adsorbent (Conditions: Initial MB concentration200 mg/L, pH: 5.7; adsorbent $0.2606 \mathrm{~g}$, volume $100 \mathrm{~mL}$ ).

\subsubsection{Kinetic Studies}

Pseudo-first-order and pseudo-second order kinetic models were applied to know the kinetics and rate controlling steps involved in the sorption process to test the experimental data collected from time dependent adsorption study at $25^{\circ} \mathrm{C}$ (Figure 8).

By the following equation pseudo-first-order kinetic model 
is expressed:

$$
\log \left(Q_{\mathrm{e}}-\mathrm{Q}_{\mathrm{t}}\right)=\log \mathrm{Q}_{\mathrm{e}}-\mathrm{k}_{1} / 2: 303 \mathrm{t}
$$

Where, $\mathrm{Q}_{\mathrm{t}}$ and $\mathrm{Q}_{\mathrm{e}}$ are the amount of MB adsorbed $(\mathrm{mg} / \mathrm{g})$ at any time and at equilibrium, respectively, $\mathrm{k}_{1}$ is the rate constant $\left(\mathrm{h}^{-1}\right)$ of the first-order adsorption. The plot of $\log \left(\mathrm{Q}_{\mathrm{e}}\right.$ $-\mathrm{Q}_{t}$ ) against $t$ would give the value of $\log \mathrm{Q}_{\mathrm{e}}$ from intercept.

By the following equation pseudo-second-order kinetic model is expressed:

$$
\mathrm{t} / \mathrm{Q}_{\mathrm{t}}=1 / \mathrm{k}_{2} \mathrm{Qe}^{2}+\mathrm{t} / \mathrm{Qe}
$$

Where $\mathrm{k}_{2}$ (g/h.mg) is the rate constant of the pseudo second order adsorption. According to the pseudo -second order equation a plot of $t / Q_{t}$ against $t$ would give $1 / Q_{e}$ from the slope. Pseudo-first order kinetic plots is presented in Figure 9 and pseudo-second-order kinetic plots is shown in Figure 10. Pseudo-first order and pseudo-second-order kinetic parameters are shown in Table 1.

\begin{tabular}{|c|c|c|c|c|c|c|}
\hline \multirow{2}{*}{$Q_{\mathrm{e}}(\exp ).(\mathrm{mg} / \mathrm{g})$} & \multicolumn{3}{|c|}{ Pseudo-first-order rate constant } & \multicolumn{3}{|c|}{ Pseudo-second-order rate constant } \\
\hline & $Q_{\mathrm{e}}$ (theor.) (mg/g) & $K_{1}\left(h^{-1}\right)$ & $\mathbf{R}^{2}$ & $Q_{\mathrm{e}}($ theor.) (mg/g) & $k_{2}\left(\mathrm{~g} \mathrm{~h}^{-1} \mathrm{mg}^{-1}\right)$ & $\mathbf{R}^{2}$ \\
\hline 73.85 & 69.66 & 0.278663 & 0.977 & 83.33 & 0.002057 & 0.947 \\
\hline
\end{tabular}

Table 1. The pseudo-first-order and pseudo-second-order rate constants for MB adsorption by sulfonated-GMA-g-PE adsorbent.

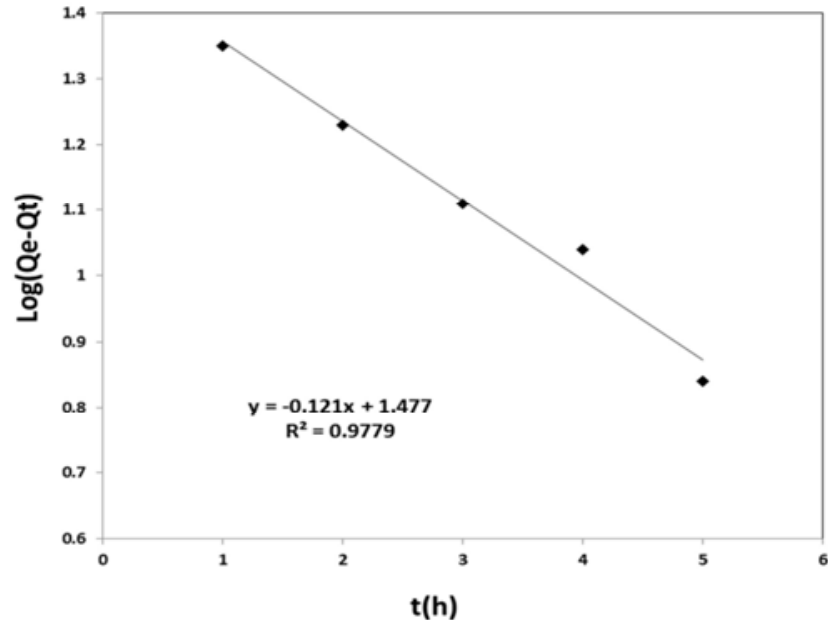

Figure 9. Pseudo first-order plot for MB adsorption.

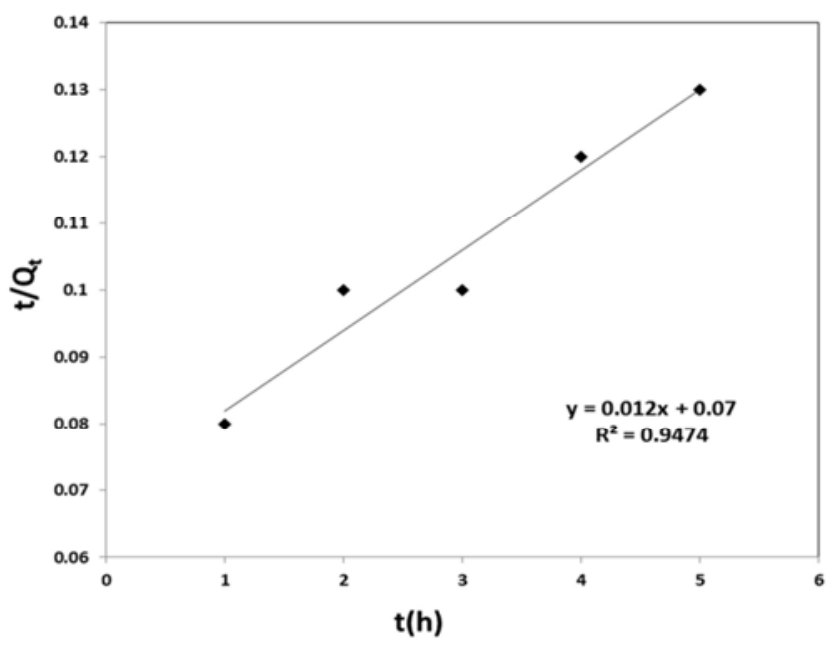

Figure 10. Pseudo second-order plot for MB adsorption.

With respect to correlation coefficients $\mathrm{R}^{2}$ the pseudo-firstorder model (0.977) gives better description of the $\mathrm{MB}$ adsorption on sulfonated-GMA-g-PE compared to pseudosecond-order kinetic model (0.943). It can also observed that the theoretical $\mathrm{Q}_{\mathrm{e}}$ value (69.66) calculated from the pseudofirst order kinetic model (Figure 9) meets well with the investigated value (73.85) whereas theoretical $Q_{e}$ value
$(83.33 \mathrm{mg} / \mathrm{g})$ calculated from the pseudo-second-order kinetic model (Figure 10) is much higher than experimental value $(73.85 \mathrm{mg} / \mathrm{g})$. This implies that MB uptake capacity of sulfonated-GMA-g-PE pursued pseudo-first order rate process and the sorption process might have occurred by both physical and chemical adsorptions.

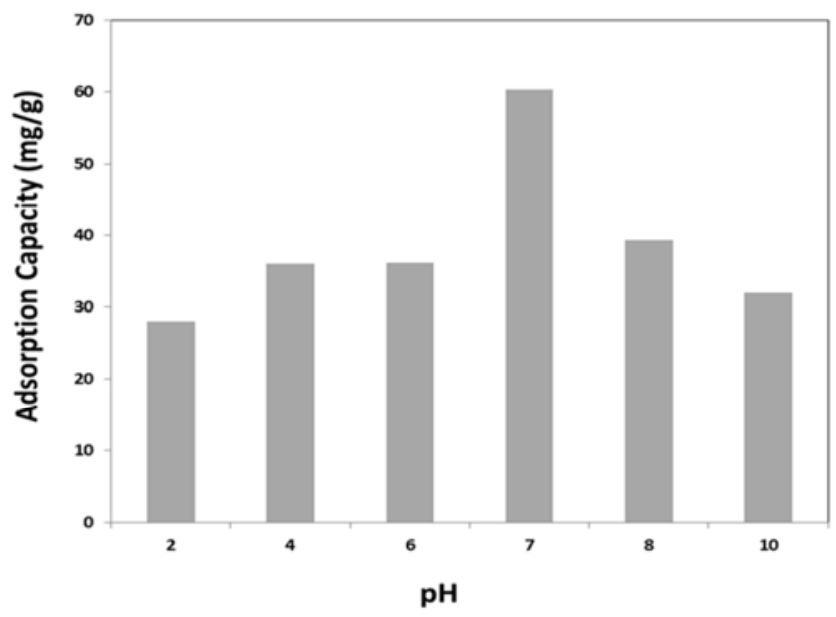

Figure 11. Effect of $p H$ on $M B$ adsorption (Initial MB concentration of 200 ppm and contact time of $24 \mathrm{~h}$, adsorbent $0.04 \mathrm{~g}$, volume $20 \mathrm{~mL}$ ).

\subsubsection{Effect of $\mathrm{pH}$ on $\mathrm{MB}$ Adsorption}

There is excessive consequence of $\mathrm{pH}$ of the medium on sorption capacity of the grafted sorbent. At different $\mathrm{pH}$ values, because of protonation and deprotonation of sulfonate ions, the surface arrangement of the adsorbent could be exaggerated and could exist in dissimilar forms which can affect the sorption capacity. The effect of $\mathrm{pH}$ on $\mathrm{MB}$ adsorption at initial MB concentration $200 \mathrm{ppm}$ and contact time $24 \mathrm{~h}$ is shown in figure 11 . It was seen that the $\mathrm{MB}$ uptake of the adsorbent increases from $\mathrm{pH}$ range 2 to 7 . At $\mathrm{pH}=7$ maximum adsorption of $\mathrm{MB}$ was observed. At low $\mathrm{pH}$ the adsorption capacity of the adsorbent is low, because of more protonation of sulfonate ions. With the increases of $\mathrm{pH}$ adsorption of $\mathrm{MB}$ increases, because of the deprotonation (forming $\mathrm{SO}_{3}$ ions) of the modified sulfonated $\mathrm{PE}$ adsorbent which attracts the positively charged $\mathrm{MB}$ ions. At higher $\mathrm{pH}$ (more than 7) the adsorption capacity of the adsorbent decreases because at higher $\mathrm{pH}$ in basic media positively 
charged $\mathrm{MB}$ attracted by $\mathrm{OH}^{-}$ions and then it is less attracted by negatively charged sulfonate ions.

\subsubsection{Effect of Initial MB Concentration on Adsorption}

Figure 12 shows the variation of $\mathrm{MB}$ uptake with the initial MB concentration (at initial pH 5.7 and time $48 \mathrm{~h}$ ). It can be illustrated that with the raise of MB concentration, the adsorption amount of MB also raised. The reason behind this outcome is that the sites of chelation on the adsorbent surface become saturated when the concentration reaches higher value. When the chelating sites become occupied there remains no sites unoccupied for further sorption of dye.

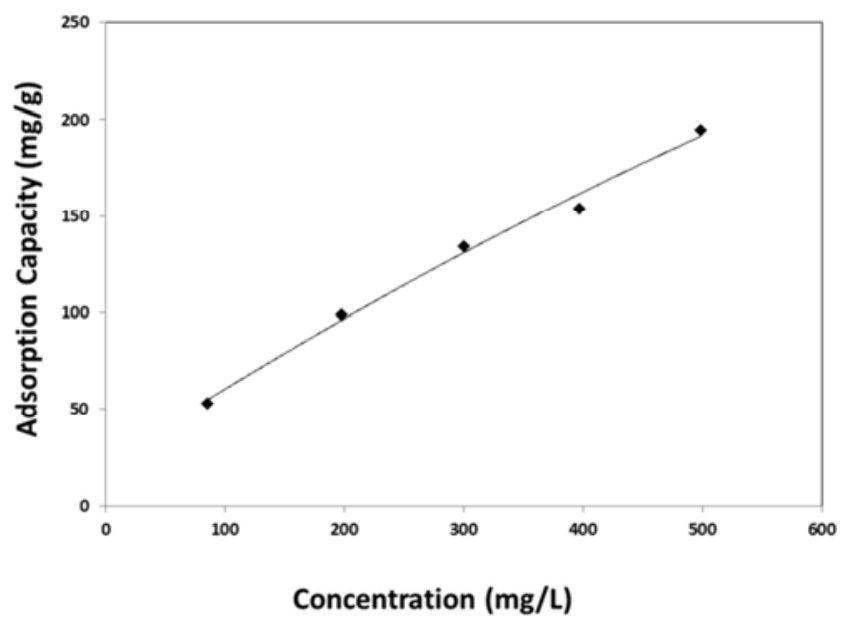

Figure 12. Effect of initial MB concentrationon the adsorption capacity ( $p H$ 5.7 and time $48 \mathrm{~h}$, adsorbent $0.022 \mathrm{~g}$, volume $20 \mathrm{~mL}$ ).

\subsubsection{Adsorption Isotherms}

The interactive relationship between adsorbent and adsorbate, surface homogeneity/heterogeneity of the adsorbent can be explained by adsorption isotherms. Langmuir and Fruendlich isotherm models are used to infer MB adsorption data.

The linear form of the Langmuir isotherm model is expressed by the following equation:

$$
\frac{C e}{Q e}=\frac{C e}{Q m}+\frac{1}{Q m b}
$$

Where, $C_{e}$ is the equilibrium concentration $(\mathrm{mg} / \mathrm{L}), \mathrm{Q}_{\mathrm{m}}$ is the monolayer saturation adsorption capacity of the adsorbent $(\mathrm{mg} / \mathrm{g}), \mathrm{Q}_{\mathrm{e}}$ the equilibrium adsorption capacity $(\mathrm{mg} / \mathrm{L})$ and $\mathrm{b}$ the Langmuir adsorption constant $(\mathrm{L} / \mathrm{mg})$. Figure 13 shows the plot of $\mathrm{C}_{\mathrm{e}} / \mathrm{Q}_{\mathrm{e}}$ versus $\mathrm{C}_{\mathrm{e}}$ drawn from the investigational data shown in Figure 12. The relationship between $C_{e} / Q_{e}$ and $C_{e}$ is linear which indicates that the Langmuir adsorption isotherm is obeyed by the adsorption behaviour. The measured values of $\mathrm{Q}_{\mathrm{m}}, \mathrm{b}$ and $\mathrm{R}^{2}$ obtained from the intercept and slope of the straight line are shown in table 2. From the straight line of the Langmuir isotherm model it is predicted that the adsorption data suits the Langmuir isotherm model as its correlation coefficient $\left(\mathrm{R}^{2}\right.$ 0.907) is close to unity. Overall, the Langmuir isotherm model can explain the adsorption of MB by the sulfonatedGMA-PE adsorbent. The utmost adsorption capacity of the adsorbent is $500 \mathrm{mg} / \mathrm{g}$.

The separation factor $\left(\mathrm{R}_{\mathrm{L}}\right)$ which is called dimensionless constant is an essential factor for Langmuir isotherm model. That describe the sorption character as favorable $\left(0<\mathrm{R}_{\mathrm{L}}<1\right)$, unfavorable $\left(\mathrm{R}_{\mathrm{L}}>1\right)$, linear $\left(\mathrm{R}_{\mathrm{L}}=1\right)$ or irreversible $\left(\mathrm{R}_{\mathrm{L}}=0\right)$. From the Table 2 it is seen that $R_{L}$ value is $(0.411 \sim 0.778)$ which is less than unity which indicates that the MB uptake capacity by sulfonated-GMA-PE adsorbent is a favourable process.

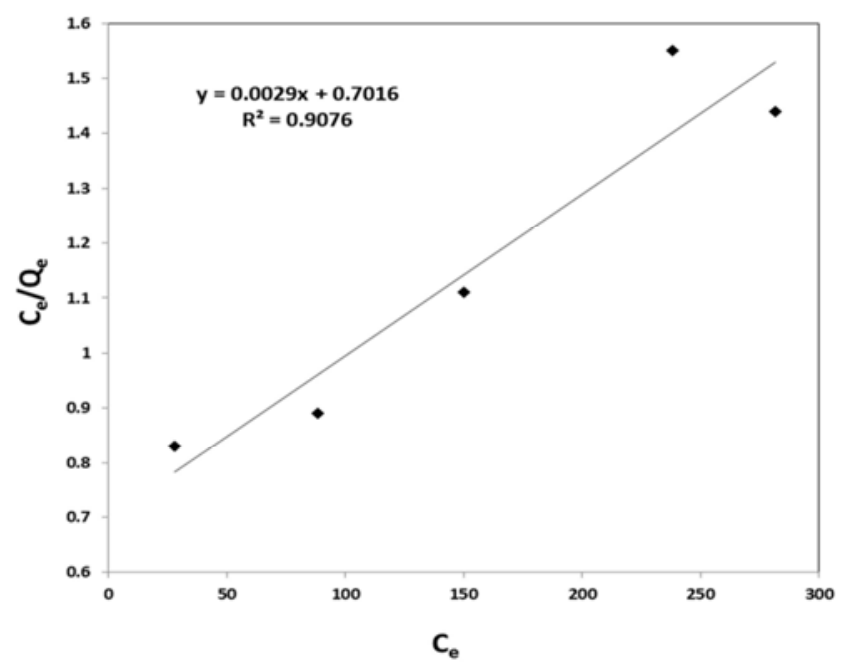

Figure 13. Langmuir isotherm model for MB adsorption.

The Fruendlich isotherm model is expressed by the following equation:

$$
\log Q \mathrm{e}=\log K_{F}+\frac{1}{\mathrm{n}} \log C e
$$

Where $C_{e}$ is the equilibrium concentration $\left(\mathrm{mgL}^{-1}\right), \mathrm{Q}_{\mathrm{e}}$ is the equilibrium adsorption capacity, the sorption capacity $\left(\mathrm{mgg}^{-1}\right)$, and $n$ is an empirical parameter. The plot of $\log \mathrm{Q}_{\mathrm{e}}$ versus $\log C_{e}$ shown in Figure 14. Figure 14 was drawn from the experimental data given in Figure 12. The $\mathrm{K}, n$, and correlation coefficients $\left(R^{2}\right)$ values are given in Table 2 .

Table 2. Langmuir and Freundlich isotherm parameters for MB adsorption.

\begin{tabular}{llllll}
\hline \multicolumn{2}{l}{ Langmuir isotherm parameters } & \multicolumn{4}{l}{ Freundlich isotherm parameters } \\
\hline $\mathbf{Q m}(\mathbf{m g} / \mathbf{g})$ & $\mathbf{b}(\mathbf{L} / \mathbf{m g})$ & $\mathbf{R}^{\mathbf{2}}$ & $\mathbf{K}_{\mathbf{F}}(\mathbf{m g} / \mathbf{g})$ & $\mathbf{1} / \mathbf{n}$ & $\mathbf{R}^{\mathbf{2}}$ \\
\hline 500.0 & 0.0028 & 0.907 & 9.20 & 0.529 & 0.988 \\
\hline
\end{tabular}

The data shown in the Table 2 indicates that there is a higher correlation coefficient $\left(\mathrm{R}^{2}, 0.988\right)$ for Freundlich model, hence it is more appropriate for recitation of the sorption of MB than Langmuir isotherm model $\left(\mathrm{R}^{2}, 0.907\right)$. This indicates that the sorption follows multilayer mode rather than monolayer mode. Which can describe that on the surface of the sorbent heterogeneous functional sites are strewn. The value of $1 / \mathrm{n}$ is less than unity (0.529) which demonstrates that Freundlich isotherm model is favorable for the adsorbent. Hence, it can be decided that Freundlich isotherm is more appropriate to explain the sorption of dye on the adsorbent. 


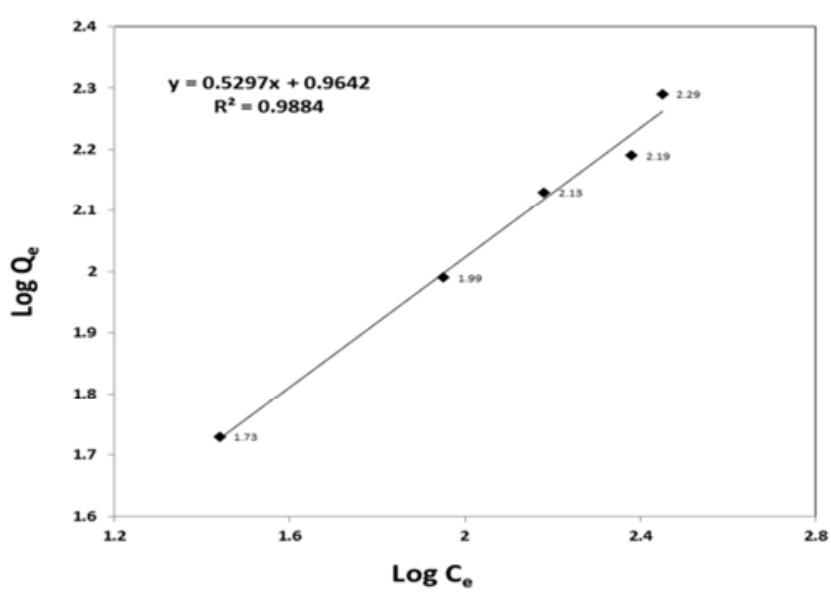

Figure 14. Freundlich Isotherm model of $M B$ adsorption on sulfonatedGMA-g-PE adsorbent.

The MB uptake capacity of the sorbent obtained from Langmuir model was $500 \mathrm{mg} / \mathrm{g}$. The adsorption capacity of MB gained in the current study together with that reported in previous studies are presented in Table 3.

Table 3. MB sorption capacity of Sulfonated GMA grafted PE film compared with some other adsorbents.

\begin{tabular}{ll}
\hline Adsorbent & Adsorption capacity (mg/g) \\
\hline Sulphonated GMA grafted nonwoven PE & 500 \\
(present study) & 127 \\
Carbon monolith [29] & 101 \\
Nanocrystalline cellulose [29] & 315 \\
Activated carbons from walnut shells [30] & 21.50 \\
Wheat shells [31] & 186.22 \\
Gulmohar (Delonix regia) plant leaf [32] & 85.16 \\
Tea waste [33] & 5.87 \\
Thermally activated coir pith carbon [34] & 225.64 \\
Jute fiber activated carbon [35] & 322 \\
\hline Acrylic acid-chitosan hydrogel [36] & \\
\hline
\end{tabular}

\subsubsection{Regeneration and Reusability}

In the current study, desorption of the adsorbent film was carried out by the usage of $2 \mathrm{M} \mathrm{HNO}_{3}$ for $24 \mathrm{~h}$ at room temperature. So, the sorbent can be returned to the initial state and reused after MB adsorption.

\section{Conclusions}

An environmental affable, economically feasible and reusable sulfonated adsorbent were prepared by radiation grafting and subsequent chemical modification and has been considered for MB adsorption from aqueous solution. The adsorption study showed that the sulfonated-GMA-g-PE adsorbent can be used as a reusable adsorbent and it has high efficiency for $\mathrm{MB}$ adsorption. From the correlation coefficient of Langmuir and Freundlich adsorption isotherms, it was suggested that the Freundlich isotherm model is better to depict the sorption process. The experimental data for the adsorption of $\mathrm{MB}$ on the adsorbent fits well with the pseudo-first-order kinetic model based on the correlation between theoretical and experimental adsorption capacity. Experiment shows that the adsorbent can be reused for $\mathrm{MB}$ adsorption from waste water.

\section{Abbreviations}

GMA-glycidyl methacrylate, Polyethylene - PE, Methylene blue - MB

\section{Acknowledgements}

We would like to convey special thanks to Gamma Source Division of Institute of Food and Radiation Biology, Atomic Energy Research Establishment.

\section{References}

[1] Ravikumar K, Deebika B, Balu K: Decolourization of aqueous dye solutions by a novel adsorbent: application of statistical designs and surface plots for the optimization and regression analysis. J. Hazard. Mater. 122, 75-93, 2005.

[2] Lee JW, Choi SP, Thiruvenkatachari R, Shim WG, Moon H: Evaluation of the performance of adsorption and coagulation processes for the maximum removal of reactive dyes. Dyes Pigm. 69, 196-203, 2006.

[3] Easton JR, Cooper P: Colour in Dye House Effluent (Alden, Oxford: The Society of Dyers and Colourists), pp. 9-21, 1995.

[4] Dutta PK: An overview of textile pollution and its remedy. Indian J. Environ. Prot. 14, 443-446, 1994.

[5] Oz M, Lorke DE, Petroianu GA: (2009) Methylene blue and Alzheimer's disease. Biochem. Pharmacol. 78, 927-932, 2009.

[6] Tsai WT, Chang CY, Lin MC, Chien SF, Sun HF, Hsieh MF: Adsorption of acid dye onto activated carbons prepared from agricultural waste bagasse by $\mathrm{ZnCl}_{2}$ activation. Chemosphere $45,51-58,2001$.

[7] Yener J, Kopac T, Dogu G, Dogu T: Adsorption of basic Yellow 28 from aqueous solutions with clinoptilolite and amberlite. J. Colloid Interf. Sci. 294, 255-264, 2006.

[8] Wang S, Boyjoo Y, Choueib A: A comparative study of dye removal using fly ash treated by different methods. Chemosphere 60, 1401-1407, 2005.

[9] Panswed J, Wongchaisuwan S: Mechanism of dye wastewater color removal by magnesium carbonate-hydrated basic. Water Sci. Technol. 18, 139-144, 1986.

[10] Ciardelli G, Corsi L, Marucci M: Membrane separation for wastewater reuse in the textile industry. Resour. Conserv. Recycl. 31, 189-197, 2000.

[11] Swaminathan K, Sandhya S, Carmalin Sophia A., Pachhade K, Subrahmanyam YV: Decolorization and degradation of $\mathrm{H}-$ acid and other dyes using ferrous-hydrogen peroxide system. Chemosphere 50, 619-625, 2003.

[12] Muthukumar M, Selvakumar N: Studies on the effect of inorganic salts on decolouration of acid dye effluents by ozonation. Dyes Pigm. 62, 221-228, 2004.

[13] Alinsafi A, Khemis M, Pons MN, Leclerc JP, Yaacoubi A, Benhammou A, Nejmeddine A: Electro-coagulation of reactive textile dyes and textile wastewater. Chem. Eng. Process 44, 461-470, 2005. 
[14] Mall ID, Srivastava VC, Agarwal NK, Mishra IM: Removal of congo red from aqueous solution by bagasse fly ash and activated carbon: kinetic study and equilibrium isotherm analyses. Chemosphere 61, 492-501, 2005.

[15] Mitchell M, Ernst WR, Rasmussen ET, Bagherzadeh P, Lightsey GR: Adsorption of textile dyes by activated carbon produced from agricultural, municipal and industrial-wastes. Bull. Environ. Contam. Toxicol. 19, 307-311, 1978.

[16] Abd-Elhamid AI, Mohammed E, El-Sadek MH, ElShanshory AA, Soliman HMA, Akl MA, Rashad M: Enhanced removal of cationic dye by eco-friendly activated biocharderived from rice straw. Appl. Water Sci. 10, Article number: 45, 2020.

[17] Hamzezadeh A, Rashtbari Y, Afshin S, Morovati M, Vosoughi M: Application of low-cost material for dsorption of dye from aqueous solution,, Int. J. Environ. Anal. Chem. 2020. doi.org/10.1080/03067319.2020.1720011.

[18] Shabaan OA, Jahin HS, Mohamed GG: Removal of anionic and cationic dyes from wastewater by adsorption using multiwall carbon nanotubes. Arab. J. Chem. 13, 4797-4810, 2020.

[19] Yadav S, Asthana A, Chakraborty R, Jain B, Singh AK, Carabineiro SAC and Susan MABH: Cationic Dye Removal Using Novel Magnetic/Activated Charcoal/ßCyclodextrin/Alginate Polymer Nanocomposite. Nanomaterials 10, 170, 2020 doi: 10.3390/nano10010170.

[20] Goel NK, Kumar V, Misra N, Vershney L: Cellulose based cationic adsorbent fabricated via radiation grafting process for treatment of dyes waste water. Carbohydr. Polym. 24 Jun 2015, 132, 444-451, 2015. DOI: 10.1016/j.carbpol.2015.06.054.

[21] Kumar R, Sharma RK, Singh AP: Synthesis and characterization of cellulose based graft copolymers with binary vinyl monomers for efficient removal of cationic dyes and Pb(II) ions. J. Polym. Res. 26, Article number: 135, 2019.

[22] Lertsarawut $\mathrm{P}$, Hemvichian $\mathrm{K}$, Rattanawongwiboon $\mathrm{T}$, Suwanmala P: Dye adsorbent prepared by radiation-induced graft polymerization of acrylic acid onto carboxymethyl cellulose. J. Phys.: Conf. Ser. 1285 012023, 2019.

[23] Zhu L, Guan C, Zhou B: Adsorption of Dyes onto Sodium Alginate Graft Poly(Acrylic Acid-co-2-Acrylamide-2-Methyl Propane Sulfonic Acid)/ Kaolin Hydrogel Composite. Polym. Polym. Compos. 25, 627-634, 2017.

[24] Dong C, Li W, Yuhong M, Wantai Y: Super-adsorbent material based on functional polymer particles with a multilevel porous structure. NPG Asia Mater. 8, e301, 2016.
[25] Hsieh L, Shinawatra YM, Castillo MD: Postirradiation polymerization of vinyl monomers on poly(ethylene terephthalate). J. Appl. Polym. Sci. 31, 509-519, 1986.

[26] Bari EMA, Sarhan AA and Razik HHA: Effect of graft copolymerization of 2-hydroxyethyl methacrylate on the properties of polyester fibers and fabric. J. Appl. Polym. Sci. $35,439-448,1986$.

[27] Nasef MM: Gamma radiation-induced graft copolymerization of styrene onto poly (ethylene terephthalate) films. J. Appl. Polym. Sci. 77, 1003-1012, 2000.

[28] Ke X, Drache M, Gohs U, kunz U, Beuermann S: Preparation of Polymer Electrolyte Membranes via Radiation-Induced Graft Copolymerization on Poly(ethylene-alttetrafluoroethylene) (ETFE) Using the Crosslinker N,N'Methylenebis (acrylamide), Membranes 8 (4), 102, 2018 https://doi.org/10.3390/membranes8040102.

[29] He X., Male KB, Nesterenko PN, Brabazon D, Paull B, Luong JHT: Adsorption and desorption of methylene blue on porous carbon, monoliths and nanocrystalline cellulose. ACS Appl. Mater. Interfaces 5, 8796-8804, 2013.

[30] Yang J, Qiu K: Preparation of activated carbons from walnut shells via vacuum chemical activation and their application for methylene blue removal. Chem. Eng. J., 165, 209-217, 2010.

[31] Bulut, Y, Aydin HA: A kinetics and thermodynamics study of methylene blue adsorption on wheat shells. Desalination 194, 259-267, 2006

[32] Ponnusami V, Gunasekar V, Srivastava SN: Kinetics of methylene blue removal from aqueous solution using gulmohar (Delonix regia) plant leaf powder: Multivariate regression analysis. J. Hazard. Mater. 169, 119-127, 2009.

[33] Uddin MT, Islam MA, Mahmud S, Rukanuzzaman M: Adsorptive removal of methylene blue by tea waste. J. Hazard. Mater. 164, 53-60, 2009.

[34] Kavitha D, Namasivayam C: Experimental and kinetic studies on methylene blue adsorption by coir pith carbon. Bioresour. Technol. 98, 14-21, 2007.

[35] Senthilkumaar S, Varadarajan PR, Porkodi K, Subbhuraam CV Adsorption of methylene blue onto jute fiber carbon: kinetics and equilibrium studies. J. Colloid Interf. Sci. 284, 78-82, 2005.

[36] Rahman N, Dafader NC, Marjub MM, SultanaS, Miah AR, Abser MN, Chowdhury U, Rahman MO: Efficiency of biodegradable acrylic acid-chitosan hydrogel in eliminating methylene blue from wastewater. J. Polym. Sci. Technol. 3, 5$10,2018$. 